\title{
A Quick Determination Method of Reloaded Pistol Cases by Observational Studies: A Precaution for Forensic Crime Scene Investigation
}

\section{John Wang}

Professor, California State University Long Beach, Criminal Justice/Forensic Science, Long Beach, USA

*Corresponding author: John Wang, California State University Long Beach, Criminal Justice/Forensic Science, 1250 Bellflower Blvd., Long Beach, 90840, USA, Tel: 562-985-4741; E-mail: zwang2@csulb.edu

Received date: August 31, 2016; Accepted date: October 17, 2016; Published date: October 24, 2016

Copyright: @ 2016 Wang J, et al. This is an open-access article distributed under the terms of the Creative Commons Attribution License, which permits unrestricted use, distribution, and reproduction in any medium, provided the original author and source are credited.

\begin{abstract}
A quick determination whether a fired cartridge case is a reloaded case or not has several practical implications for responding officers, crime scene technicians, and criminal investigators in the field. Such a determination would give them a precaution: (1) The fired case may have been be fired by one or several weapons. (2) A quick determination of reloaded and fired pistol cases should assist criminal investigation in narrowing down the type of ammunition used, the type of suspects involved, and a possible link between the reloaded case(s) and the reloading machine at the suspect's residence. (3) If the case goes to the court, the expert opinion from the examiner would be challenged heavily by the defense. Currently, little information and research is available on the topic. Based on the observational examinations of reloaded and fired pistol cartridge cases $(\mathrm{N}=100)$ with three types of calibers $(.45, .40$, and $9 \mathrm{~mm}$ ), this study offers three practical guidelines for a quick determination of these reloaded and fired cases by naked eyes or a magnifier. These three guidelines should be relevant and useful in identifying reloaded and fired pistol cartridge cases at the scene and as reference later in comparing them in the lab to improve criminal investigations.
\end{abstract}

Keywords: Forensic crime scene investigation; Firearm examination Reloaded and fired pistol cartridge cases; Fire pin impression; Extractor marks; Ejector marks; Ring/Reaming mark

\section{Introduction}

Since approximately $60 \%$ of homicides in the United Sates are committed with the aid of a firearm, a determination at the scene and examination in the lab has become one of the most challenging fields in the discipline of forensic sciences in recent years [1]. For example, a fired cartridge case from a semi-automatic pistol was found at a shooting scene. On the fired case, several marks would usually bear forensic values, such as the firing pin impression, the extractor mark, and the ejector mark.

Further, if a pistol was recovered from a suspect's possession or from a specific location (e.g. in the woods) near the crime scene, an examination in the lab would allow for a comparison between the fired case obtained from the scene and the fired cases from the test fire with the weapon for an inclusionary or exclusionary decision.

In theory if the marks on the fired case from the scene match the marks from the test-fired case, it can be stated with a very high degree of probability that the gun found was the same weapon that fired the cartridge case at the scene, which has been well presented in the literature [2-4].

However, one of the new challenges to the crime scene investigation is the situation where a fired cartridge case found on the scene bears more than one extractors mark and more than one ejector marks.

Thus, it is the focus of this study to provide a quick determination method of reloaded and fired pistol cartridge cases that have been fired and reused by more than one firings or more than one firearms.

\section{Why reloading?}

Several reasons may account for reloading fired cases. For amateur, casual or weekend shooters, reloading may not be an economic factor but rather a personal hobby because it takes longer time and more labor to reload. On the other hand, professional shooters choose to reload for a modified performance, such as increasing the velocity by adding more powder for a deeper penetration. Some target shooters might want to increase accuracy by using a special type of gunpowder for best "shot-to-shot consistency." Of course, the last category of reloaders or users is those who want to reload so that original extractor and ejector marks become more difficult to trace and compare. In reality, several real cases have indicated that criminals today have already begun such attempts in using reloaded pistol cartridge cases to divert police in their criminal investigation.

\section{Evidential challenges to forensic investigation at the scene}

Fired cartridge cases from pistols, revolvers, and rifles can be reloaded for reuse, and there is no information on any successful reloading of shotgun shells. Cartridge cases made of brass are the most commonly recycled cases because the brass case is not hard and can be recapped for a new primer. While studies of reloaded and fired revolver and rifle cases will be next projects for the author, this study focuses on reloaded and fired pistol cartridge cases as a first step and provides necessary information on the reloading process and a quick determination method in the field.

A quick determination of reloaded and fired pistol cartridge cases is very important for a crime scene investigation, especially for a small police agency where firearms expertise is not available. When a dedicated shooting incident occurs, responding officers, crime scene technicians, and criminal investigators need to properly document the condition of the scene and preserve evidence for a later examination in 
the lab and a reconstruction of the scene. As with any shooting crime scene, a quick determination of evidence is highly important, especially concerning reloaded and fired cartridge cases. Reloaded and fired pistol cartridge cases are the most commonly found cases at shooting scenes and thus should be properly identified and studied. If such a determination can be established early on, the crime scene processing will become much less complicated and dedicated for later lab examination and shooting reconstruction teams. It is highly recommended that responding officers, crime scene technicians, criminal investigators, as well as shooting reconstruction teams should not begin their work until a quick determination whether a fired cartridge case is a reloaded one has been completed. Not only does this early determination permit the crime scene technicians, investigators, and shooting reconstruction team members to focus more clearly on their area of expertise, but it also prevents them from moving in a wrong direction, which can more easily happen without such a precaution.

\section{Related legal issues}

While the laws on reloaded cartridge cases vary from country to country, reloading in the United States is completely legal and covered under the Second Amendment of the Constitution. However, when a fired cartridge case bears multiple extractor and ejector marks due to being reloaded and re-fired, several legal issues may also arise. First, almost all the manufacturers of ammunition refuse to accept any "strict liability" for a cartridge that has been reloaded. Thus, any reloaded cartridge voids the manufacturer's warranty, making the individual, not the manufacturer, responsible for any damage to the weapon and/or to any person affected. Second, depending on the jurisdiction, malice could be implied in a self-defense if any person is injured or killed due to a firearm that fires a reloaded cartridge. Finally, if a police officer fires a reloaded cartridge, the same principle applies because the firearm examiner may have the difficulty in determining the sequential order of shootings for reconstruction of the shooting incident forensically [5]. Finally, if the case goes to trial, the firearm examiner would also face more legal questions from the defense. Therefore, these practical situations and related legal issues justify a research project to explore a quick determination method of reloaded and fired pistol cartridge cases at scenes.

\section{Materials and Methods}

The current study consists of four parts: (1) Establishment of operational definitions of terms involved in this project; (2) Observation of a reloading process; (3) Sample collection of reloaded and fired pistol cartridge cases; (4) Observation and examination of the collected reloaded and fired pistol case samples.

\section{Operational Definitions}

For the sake of the discussion for this project, several operational definitions have been modified and adopted to help understand the reloading practice [6,7].

While ammunition is a general term for live cartridges of different calibers, grains of gunpowder, bullet shapes, and types of firearms, a cartridge refers to a single unit of live or loaded round containing a case, a primer, a projectile (bullet), and propellant (gunpowder).

A case is the lower part of the cartridge that holds the bullet on the top, the propellant within, and the primer at the base. A cartridge case can be made of many types of metal materials, such as brass, aluminum, nickel, copper, or even plastic. Currently, only a cartridge case made of brass is a commonly used case for reloading. A fired case refers to a case that bears many marks from the firing mechanism.

A bullet, also known as a projectile, is the top part of the cartridge with many types of materials (plain lead, full metal jacketed, or semimetal jacketed), and many shapes of designs (pointed, coned, hollow pointed, or hydra-pointed).

A round is the unit for a single cartridge. For example, many states have laws to ban a magazine that can hold more than ten rounds of cartridges for a civilian use.

A primer is the ignition component contained in a cup-shape container located in the pocket at the cartridge base. The primary explosive (lead styphnate, barium nitrate, and antimony sulfide) inside the primer is used to ignite the propellant (gunpowder) after firing.

A firing pin impression refers to the negative indentation mark (a coned shape or a rectangular shape by the Glock series) on the primer surface when it is struck by the firing pin upon a firing. The negative mark can reflect the firing pin's unique shape due to its different levels of use, wear, and maintenance, resulting in an impression, a scrape, or a drag mark.

An extractor mark is produced inside the groove area of the fired cartridge case when the extractor grabs or holds the fired case backward for ejection. The negative impression can reflect a unique mark from the extractor in terms of its shape, striation, size, and depth.

An ejector mark is formed usually on the rim or edge areas of the fired case when the fired case is pushed backward by the explosive gas and mechanical actions, then hit onto the ejector, and finally expelled/ thrown out of the right side of the firearm. The negative impression can reflect a unique mark from the ejector in terms of its shape, striation, size, and depth.

\section{Observation of a reloading process}

Since reloading is a complicated process, an observation of the actual process was undertaken by the author at a gun owner's garage to gain the necessary visual background information. A reloaded and fired cartridge case is defined as a fired case where its primer, powder, and bullet have been reloaded for a reuse purpose. Reloading a fired cartridge case is a detailed systematic process that requires special tools for a new cartridge. The preferred or safer case material is the case made of brass and the preferred powder is the smokeless powder. Replacement of bullets and primers are regular items that can be purchased from the market. While there exist several reloading methods, such as by a commercial reloading machine with a reaming method or a hand-reloading machine with a swaging method, the following summary describes the major steps of a commercial reloading machine with a reaming method. The following summaries are used to indicate the important steps or acts that may have forensic implications for the current study.

Case tumbler machine: It is a tunnel shaped basin that cleans previous gunshot residues (GSR) on fired or used cartridge cases by eradicating the oxidation, a chemical reaction in which oxygen is added to an element of compound and polishes the case at the same time.

Lubricating the case: Place the cleaned fired cartridge case into the lubricant to reduce friction for later bullet insertion. However, if the 
die is made of a carbide material, there is no need for this lubricating process.

Reloading the case: The press machine has to grip the fired case and start the reloading process. Sometimes, a gripping mark at the base of the case can be seen.

Resizing the deformed case: Certain firearms produce a slant dent on the mouth of the case that is caused by the ejector or the case mouth may become bigger after the gas expands the fired case after the firing. This kind of case needs to be resized by a special die to reshape the deformed fired case mouth back to its original size. Sometimes, the resizing die produces a resizing mark around the mouth of the case.

De-priming or de-capping: A die removes the fired primer from the fired cartridge case, meaning the die chips off or punches out the fired primer for a new primer to be loaded in, producing a ring mark by reaming the edge around the primer pocket.

Brushing: Clean the primer pocket and remove any residue.

Recapping: A new primer is loaded and pressed into the primer pocket by a priming tool.

Re-powdering: New gunpowder is put into the reloaded case. The amount of powder can be varied in terms of amount and type of gunpowder. Measure the proper amount of powder, usually smokeless powder according to the manufacturer's specifications. Be careful not to put too much or too little powder because each can cause potential danger.

Seating the bullet: The case is now placed in the holder and a new bullet is placed into the case mouth by a bullet seater die. The insertion follows the principle of proper overall length (OAL) on the cartridge and line up with the cannelure, which is a groove on the bullet from certain manufactures.

Crimping the case: The pressing machine crimps the case at the level of the case mouth. Equivalent to the level of the bullet bottom to ensure the case mouth tightens the bullet. The bullet seating die crimps the casing to ensure that the bullet remains in place. Sometimes, a crimping mark around the circumference of the fired cartridge case can be noticed.

\section{Sample collection}

The study followed six steps to ensure a random sample collection. First, under the purposive sampling, the author approached three local indoor shooting ranges and purchased or collected only reloaded and fired pistol cartridge cases $(\mathrm{N}=100)$, consisting of three calibers $(.45$, 40 and $9 \mathrm{~mm}$ ). Second, due to the limits of time and resources, fifty reloaded and fired pistol cartridge cases were randomly selected from the collected cases $(\mathrm{N}=100)$ with the author's eyes blinded to avoid any selection bias. Third, the author examined visually each of the fiftyfired cases and attempted to detect any unique marks or characteristics as working identifiers. As a result, three types of major marks from the fifty reloaded and fired pistol cartridge cases were identified. Next, the author mixed the fifty reloaded and fired pistol cartridge cases with another fifty regular fired pistol cartridge cases as control samples and placed them into a box. The author's research assistant made a special mark on each of the control samples, which was unknown to the author. Using the three types of identifiers or marks (to be explained later), the author then examined the one hundred mixed fired pistol cartridge cases and was able to determine with naked eyes which fired case was a reloaded and fired pistol cartridge case $(\mathrm{N}=50)$. This step was designed to resemble a real crime scene setting. The author's research assistant then verified the author's determination of the fifty reloaded and fired pistol cartridge cases. Fifth, after the author successfully separated the fifty reloaded and fired pistol cartridge cases, a stereo microscope with a magnification of $10 \mathrm{X}$ in the author's lab was used for detail descriptions of the three marks from the fifty reloaded and fired pistol cartridge cases. Finally, three working guidelines were established for a quick determination method at the scene based on the microscopic observations. A digital viewer with a magnification of $25 \mathrm{X}$ was employed for a confirmatory verification of the observational results and for image illustrations for this study. The following is a summary of the three working guidelines based on observations of the fifty reloaded and fired pistol cartridge cases.

\section{Observational results}

A reloaded cartridge case is the one that has been previously fired and the case retrieved for reuse purposes. Certainly, a reloaded case at the scene has been a conundrum for crime scene investigators because such cases are not easily identified at the crime scene and definitely pose problems to the next forensic ballistic examination in the lab. In other words, reloaded ammunition is a type of ammunition that uses recycled or reused cartridge cases to house a new primer, power, and bullet for a reusable cartridge. Since some shooters choose to reload cartridge cases for different reasons, it is not uncommon for a cartridge case to be reloaded two or three times and there is no consensus on how many times a fired case can be reloaded. While a general framework of firearms criteria have been well established $[8,9]$, no existing guidelines can be found on a quick determination of reloaded and fired pistol cartridge cases at scenes.

\section{Three guidelines for a quick determination of reloaded pistol casings at scenes}

When a cartridge case is being reloaded, the fired primer is removed from the base of the case and a new primer is inserted in its place. The powder is then refilled and a new bullet is inserted into the mouth of the case. As a result, the reloading process produces certain marks that can be used for a quick determination of a reloaded cartridge case at the scene.

\section{1) The ring mark}

During the reloading process, the old primer is removed from the primer pocket and is replaced by a new primer (Step 5: De-priming above). In other words, the die knocks off the old fired primer to give a place for a new primer and thus produces a ring around the primer pocket. This ring mark can serve as a typical identifier to indicate that the cartridge case has been reloaded or reused. Upon close observation, three different types of ring marks can be identified. A new die on the press machine produces a smooth and shinning ring around the primer pocket (Figure 1). More often, if the die is in its middle age, a series of concentric striation lines can be observed on the surface of the ring on the rim of the new primer (Figure 2). Finally, a ring with a rough slope or surface suggests that the reloading die/press is getting old or is a poorly built machine (Figure 3). These wear patterns can later be considered as individual characteristics to link a reloaded case to the reloading machine at a potential suspect's home. Essentially, if a ring mark is observed, it definitely indicates that the fired pistol case possesses one of the characteristics of a reloaded and fired pistol cartridge case. 
Citation: Wang J (2016) A Quick Determination Method of Reloaded Pistol Cases by Observational Studies: A Precaution for Forensic Crime Scene Investigation. J Forensic Res 7: 344. doi:10.4172/2157-7145.1000344

Page 4 of 5

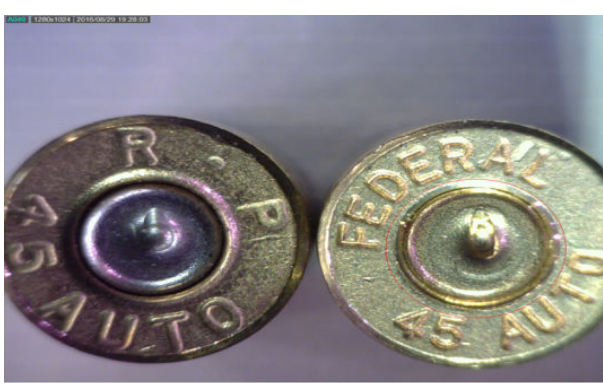

Figure 1: A comparison between a regular case on the left and a reloaded and fired pistol cartridge case on the right with a shining ring mark around the primer pocket by a new die.

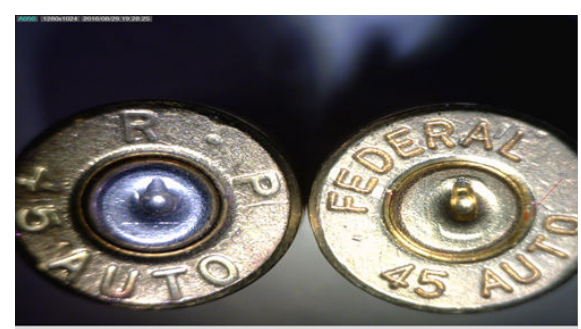

Figure 2: A comparison between a regular case on the left and a reloaded and fired pistol cartridge case on the right with a ring mark with concentric striation lines around the primer pocket by a middle aged die.

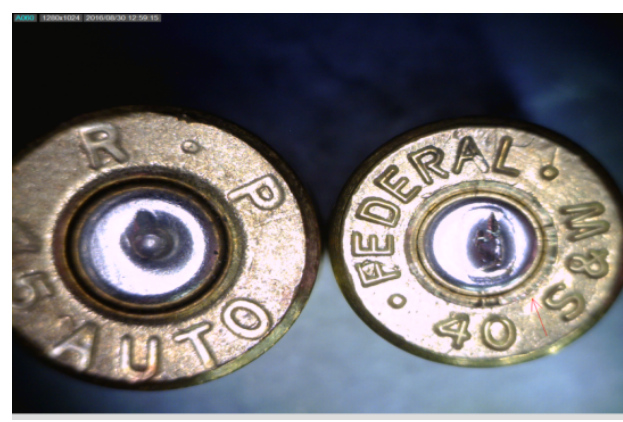

Figure 3: A comparison between a regular case on the left and a reloaded and fired pistol cartridge case on the right with a ring mark with a rough slope or surface around the primer pocket by an old die.

\section{2) Multiple extractor marks}

After the determination of the ring mark around the primer pocket, the next step is to locate multiple extractor marks at the bottom of the groove near the cartridge base. In principle, upon each firing the extractor holds the cartridge groove and pulls the case back by the gas, producing only one extractor mark. Thus, if the officer, the technician, or the investigator holds the fired case horizontally and turns it around, a claw-shape mark can be observed with naked eyes or a magnifier. If

J Forensic Res, an open access journal more than one extractor marks are present, it definitely indicates that the fired case possesses one of the characteristics of a reloaded and fired pistol cartridge case (Figure 4).

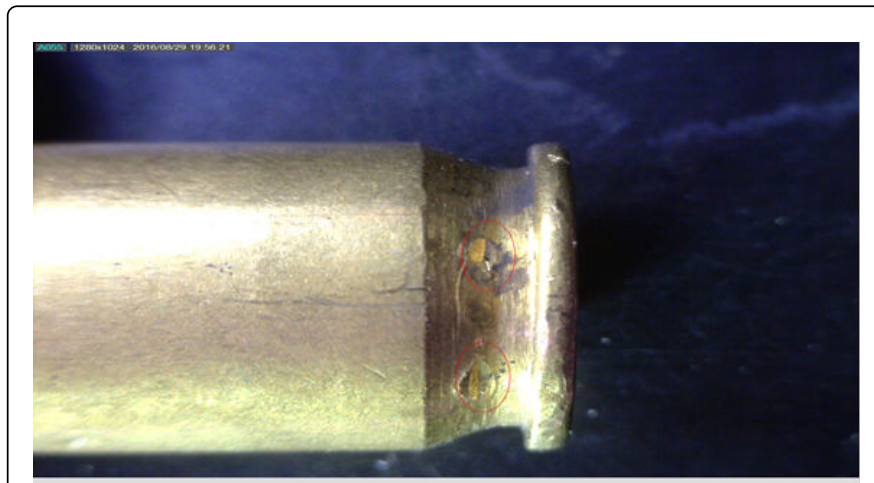

Figure 4: Two extractor marks can be observed at the groove bottom of a reloaded and fired pistol cartridge case.

\section{3) Multiple ejector marks}

Finally, multiple ejector marks can be seen at the edge of the fired case base by multiple firings. In principle, once the extractor holds the case groove and pulls it back by the gas, the fired case hits the ejector positioned on the left side of the bolt, which in turn ejects the fired case out of the chamber through the ejector port, usually to the right side of the shooter. As a result, the ejector produces only one ejector mark at the edge or rim of the case base upon each firing. Again, if one holds the case base up, a triangle-shape or a straight indentation mark can be noticed with naked eyes or a magnifier. If more than one ejector marks exist, it definitely indicates that the fired case possesses one of the characteristics of a reloaded and fired pistol cartridge case (Figure $5)$.

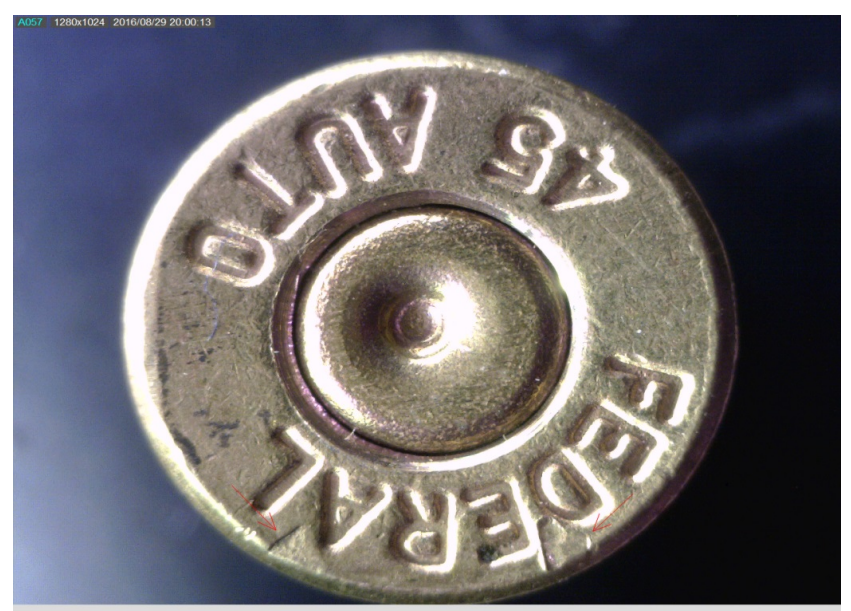

Figure 5: Two ejector marks can be observed at the edge of a reloaded and fired pistol cartridge case.

In sum, the three types of marks were all present on all fifty reloaded and fired pistol cartridge cases $(.45, .40$ and $9 \mathrm{~mm}$ calibers $)$ and are recommended here as three guidelines for a quick determination method at the scene. Practically speaking, if all the three types of 
Citation: Wang J (2016) A Quick Determination Method of Reloaded Pistol Cases by Observational Studies: A Precaution for Forensic Crime Scene Investigation. J Forensic Res 7: 344. doi:10.4172/2157-7145.1000344

Page 5 of 5

marks exist on a fired case, it can be stated with a very high degree of probability that the fired case is a reloaded and fired pistol cartridge case. Further, if a gripping mark at the base of the case, a resizing mark around the mouth of the case, and/or a crimping mark around the circumference of the case are present, these three additional marks (may not be present on all reloaded and fired pistol cases) can definitely reinforce the determination.

\section{Conclusion}

This study was aimed at providing responding officers, crime scene technicians, and investigators with a quick determination method of which fired case is a reloaded and fired pistol cartridge case. In theory, if a cartridge case has been reloaded, these personnel should be able to make a quick determination at the scene by naked eyes or a magnifier based on the three practical guidelines provided herein. These guidelines would also assist firearm examiners in the lab to perform the following comparisons. In these circumstances, much of the initial crime scene processing should go forward as normal [10]. However, the processing steps should be both prudent and appropriate when reloaded and fired pistol cartridge cases are present. Therefore, the guidelines are the important and necessary precaution that should be taken during the initial processing of the crime scene. Once adhered to, the three working guidelines would improve crime scene investigations and later assist firearms examiners and shooting reconstruction team members by better preserving evidence of value. Finally, three new directions will be the author's future research attempts. First, a project will focus on examining reloaded rifle and revolver cartridge cases and examining reloaded and fired cases from multiple firing marks from the same or different firearms. Second, another project will be aiming at examining reloaded and fired cartridge cases by the swaging method from a simple hand-reloading machine. Finally, the author will explore the possibility of quantitative comparison and examination methods of reloaded and fired cartridge cases in the lab.

\section{Acknowledgements}

Appreciation is extended to the sabbatical leave and the RSCA Award granted from College of Health and Human Services at California State University-Long Beach, U.S.A. Also, special thanks should be given to the two reviewers for their valuable and professional comments and suggestions.

\section{References}

1. Blair, P, Schweit, W (2014) A study of active shooter incidents between 2000 and 2013, Texas State University and Federal Bureau of Investigation, U.S. Department of Justice, Washington DC.

2. Bonfanti S, De Kinder J (1999) The influence of the use of firearms on their characteristic marks. AFTE Journal 31: 318-323.

3. Bunch, G, Murphy, P (2003) A comprehensive validity study for the forensic examination of cartridge cases. AFTE Journal 35: 201-203.

4. Scientific Working Group for Firearms and toolmarks (SWGGUN) (2007) Firearm \& toolmark identification. Admissibility Resource Kit., Appendix I.

5. Vernick, S (2011) The role of federal preemption in injury prevention litigation. Journal of Law, Medicine \& Ethics 39: 85-88.

6. Bell S (2004) The Facts on file dictionary of forensic science. New York: Checkmark Books.

7. Brenner C (2004) Forensic science: An illustrated dictionary, New York: CRP Press.

8. Nichols G (1997) Firearm and toolmark identification criteria: A review of the literature. Journal of Forensic Sciences 42: 466-474.

9. Nichols G (2003) Firearm and tool mark identification criteria: A review of the literature, part II. Journal of Forensic Sciences 48: 318-327.

10. DeFrance S, Rosati J (2009) A practical guide to shooting scene preservation for crime scene Investigators. Journal of the Association for Crime Scene Reconstruction 15: 29-39. 